\title{
Measurements of the Principal Axis of Frozen Hemispheric Water Droplets
}

\author{
By Hiroshi Uyeda* and Katsuhiro Kikuchi
}

Department of Geophysics, Hokkaido University, Sapporo, Japan

(Manuscript received 16 March 1979, in revised form 10 November 1979)

\begin{abstract}
Freezing experiments on supercooled hemispheric water drops of an approximate $1 \mathrm{~mm}$ in diameter were carried out from a point of view of the formation mechanisms of the origin of polycrystallization of frozen cloud droplets. Hemispheric water drops were seeded with a basal plane and a prism plane of single crystalline ice of needle type in the temperature ranges of -17 to $-20^{\circ} \mathrm{C},-20$ to $-23^{\circ} \mathrm{C}$ and -23 to $-26^{\circ} \mathrm{C}$, respectively. Notable polycrystallization occurred when hemispheric water drops were seeded with basal planes of single crystalline ice of needle type. The axial angle between the $c$-axis of a seeding crystal and that of a frozen hemispheric water drop had a prominent peak around $70^{\circ}$ at all temperatures from -17 to $-26^{\circ} \mathrm{C}$. The axial angle between the $c$-axes of neighbouring two crystals making up a frozen hemispheric water drop had peaks around $70^{\circ}$, $55^{\circ}$ and $40^{\circ}$. Based upon these angles in this experiment, a possible arrangement of the $c$-axes of crystals making up a frozen water droplet was proposed.
\end{abstract}

\section{Introduction}

During recent years, interests in the formation mechanisms of the origin of polycrystalline snow crystals, that is to say, spatial dendrites, radiating assemblage of dendrites, side planes and combination of bullets have led to measurements of the axial angle between branches of polycrystalline snow crystals observationally and examinations of supercooled water droplets frozen to polycrystalline experimentally. Lee (1972) carried out careful measurements of the axial angle between spatial branches of natural polycrystalline snow crystals under a microscope using a universal stage. He found that the maximum peak in the frequency distribution of the axial angle was around $70^{\circ}$ in all types of snow crystals of spatial dendrites, radiating assemblage of dendrite, side planes and combination of bullets. Furthermore, his results were reconfirmed through the measurements by Uyeda and Kikuchi (1976b) and Kobayashi et al. (1976).

The idea that polycrystalline snow crystals

* Present affiliation: National Research Center for Disaster Prevention. above described grew from polycrystalline frozen droplets was set forth by Weickmann (1972) and Parungo and Weickmann (1973) and apart from them, Kikuchi and Ishimoto (1974) carried out the laboratory experiments regarding the growth of polycrystalline snow crystals from the frozen water droplets. Therefore, freezing experiments of water droplets are necessary to investigate the origin of polycrystalline snow crystals by comparing with the results of the axial angle between branches of natural polycrystalline snow crystals.

Laboratory experiments regarding the crystal structure and the orientation of frozen droplets on an ice surface were carried out by Hallet (1964). Higuchi and Yoshida (1966) grew prism crystals from frozen droplets impacted onto an ice substrate and they measured the axial angle between the $c$-axes of prism crystals and the ice substrate. Similar experiments in the case of dendritic crystals were done by Aburakawa and Magono (1972). They measured the axial angle between dendritic branches grown from frozen water droplets impacted on ice substrate. Further they obtained the results in which the peaks of the axial angle were approximately $80^{\circ}$ at $-20^{\circ} \mathrm{C}$ and $-28^{\circ} \mathrm{C}$ and within a range of $40^{\circ}$ and $50^{\circ}$ 
at $-10^{\circ} \mathrm{C}$. Murray and List (1972) carried out investigations of water drops frozen freely-floating in purified air in a vertical wind tunnel. And they made etch pits on the frozen water drops and obtained the distribution of crystallographic orientations; namely the angle between the $c^{\prime}$ axis, which is the projection of the $c$-axis on the plane of the examination, and a radial line from the assumed growth center. However in these experiments the axial angle between the $c$-axes of neighbouring two crystals of frozen water droplets was not measured.

Uyeda and Kikuchi (1976a) made a freezing experiment of supercooled water drops about $1 \mathrm{~mm}$ in diameter suspended at the interface of two insoluble liquids at temperature ranges of -17 to $-23^{\circ} \mathrm{C}$. They made thin sections of the frozen water drops and measured the axial angle between the $c$-axes of the neighbouring crystals of frozen water drops. And they found that the peaks of the angle were around $20^{\circ}$ to $30^{\circ}$ and around $70^{\circ}$. Further, Uyeda and Kikuchi (1978) concluded by the experiment using single crystal frost ice of needle type that the peak of the angle around $70^{\circ}$ was affected mainly by relatively cold temperatures of -20 to $-25^{\circ} \mathrm{C}$. The result that the peak around $70^{\circ}$ predominated at the temperature range of -20 to $-25^{\circ} \mathrm{C}$ agreed well with the results of direct observations that natural polycrystalline snow crystals which have the axial angle of $70^{\circ}$ between neighbouring branches were expected to grow at air temperatures below $-20^{\circ} \mathrm{C}$.

Considering the freezing experiments of water drops and the observations of natural polycrystalline snow crystals up to the present, the measurements of the following two angles on the same sample of frozen drops are essential to make clear the mechanism of the origin of polycrystalline snow crystals. The first is the axial angle between the $c$-axes of a seeding crystal and the crystals making up frozen water drops. The second is the axial angle between the $c$-axes of neighbouring two crystals constituting frozen water drops. Hallett (1964) and Higuchi and Yoshida (1966) suggested that the effect of the nucleation by seeding was different from basal planes and prism planes of ice. The difference seems to play an important role on the nucleation of supercooled water drops.

In this experiment, therefore, measurements were made to determine the axial angle between the $c$-axes of a seeding ice needle and the crystals constituting a frozen water drop, and the axial angle between the $c$-axes of neighbouring two crystals making up a frozen water drop. At the same time the difference between a basal plane and a prism plane on nucleation of supercooled drops was compared.

\section{Experimental}

The experimental apparatus is shown in Fig. 1. This apparatus was set in a cold room at the temperature ranges of -17 to $-26^{\circ} \mathrm{C}$. Distilled and de-ionized water drops were sprayed on a glass slide coated with hydrophobic film of KC88, then hemispheric water drops of the size from 0.6 to $1.0 \mathrm{~mm}$ in diameter were made on it. The drops were cooled down to the intended temperatures which were measured by a thermo-junction on the stage of the apparatus in a cold room. Then supercooled hemispheric water drops were seeded with a single crystalline ice of needle type about $1 \mathrm{~cm}$ in length prepared in advance. New ice needle was used in every seeding. The ice needle was set on a supporter fixed on a microscopic tube in order to make the direction of the $c$-axis of the needle perpendicular to the plane of the stage of the microscope. By adjusting the supporter upward and downward in this way, supercooled hemispheric water drops were seeded at around the top of them with a basal plane of the ice needle. Fig. 2 shows an example of a frozen hemispheric water drop under a polarization microscope. In order to seed the hemispheric water drop with a prism plane, a single crystal ice needle was placed on a glass slide and was moved slowly by using a pincette until to touch on a surface of a supercooled hemispheric water drop.

Frozen hemispheric water drops were cut into thin sections with the use of a small safety razor blade. The plane of the thin section was parallel

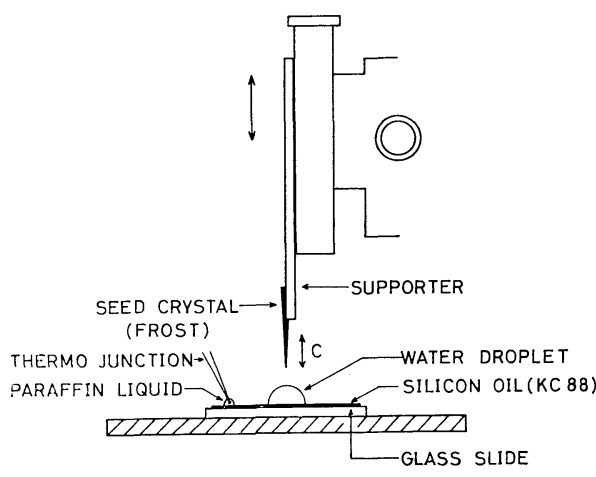

Fig. 1 Schematic figure of the experimental equipment. 


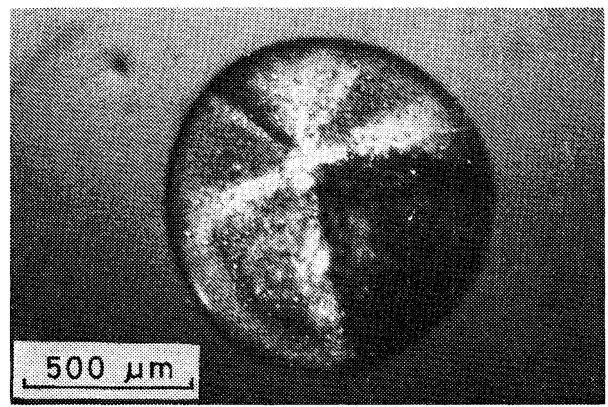

Fig. 2 An example of a frozen hemispheric water drop seeded with a basal plane of ice needle under a polarization microscope.

to the plane of a glass slide. In this experiment, thin sections were made up easily without using aniline solution, for hemispheric water drops were frozen tightly on a glass slide. Fig. 3(a) and (b) show features of thin sections of frozen water drops seeded with a basal plane and a prism plane, respectively under a polarization microscope. The orientation of each crystal of the frozen water drop was measured in the same manner as described in the previous paper (Uyeda and Kikuchi (1976 a)), while the crystals nucleated apart from seeding point were excluded in this measurement. Also the axial angle of the $c$-axes between an ice needle and each crystal of a frozen water drop, and the axial angle of the $c$-axes between neighbouring two crystals of a frozen water drop were determined with projection on Wulff's stereographic net. Here the direction of a $c$-axis of ice needle to the plane of a glass slide was easily determined because it was perpendicular to the plane of thin section when an ice needle was set on a supporter fixed on a microscopic tube and it was on the plane of a glass slide when a prism plane of an ice needle was used for seeding.

\section{Results}

From the photographs under the polarization microscope, the number ratio of polycrystalline frozen drops to single crystalline frozen drops was measured. when hemispheric water drops were seeded with basal plane of ice needle, $40 \%$ of them was polycrystalline at the temperature range of -17 to $-20^{\circ} \mathrm{C}, 64 \%$ of them at the temperature range of -20 to $-23^{\circ} \mathrm{C}$, and $75 \%$ of them at the temperature range of -23 to $-26^{\circ} \mathrm{C}$. In each case the number of drops examined was more than a hundred. Several frozen drops of them were single crystal with the

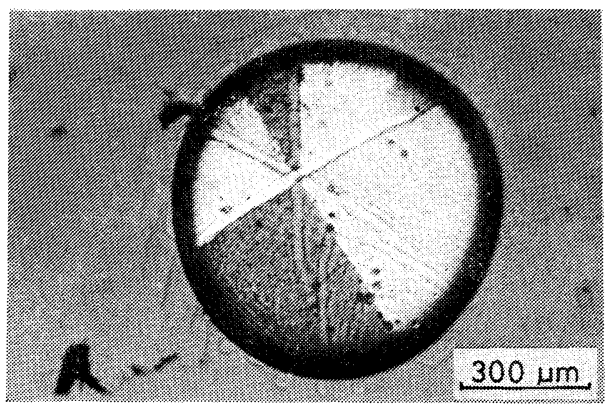

(a)

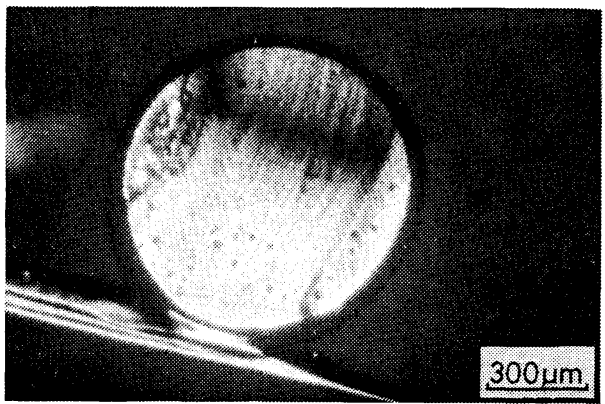

(b)

Fig. 3 The thin sections of frozen hemispheric water drops under a polarization microscope. (a) Seeded with a basal plane (b) Seeded with a prism plane of ice needle.

different $c$-axis from that of an ice needle although almost all of the single crystals had the same $c$ axis as that of the ice seeded. On the other hand, when supercooled hemispheric water drops were seeded with a prism plane of the ice needle, the percentage of polycrystalline water drops was about a half against the case where, seeded with a basal plane at all temperature ranges. In this case all single crystal have the same $c$-axis as the $c$-axis of an ice needle around a seeding point.

When the water drops froze to polycrystal by seeding with a prism plane of the ice needle, the prominent peaks were not found in the frequency distribution of the angle between the $c$-axes of neighbouring crystals of these frozen water drops. Furthermore in this case, the $c$-axis of each crystal making up frozen water drops sometimes changed gradually in the range of the angle of $15^{\circ}$. And particularly polycrystallization did not start from the seeding point as shown in Fig. 3(b). Turning to the seeding with a basal plane of an ice needle, polycrystallization commenced at the seeding point as shown in Fig. 2 and Fig. 3(a). This was ascertained by making several 

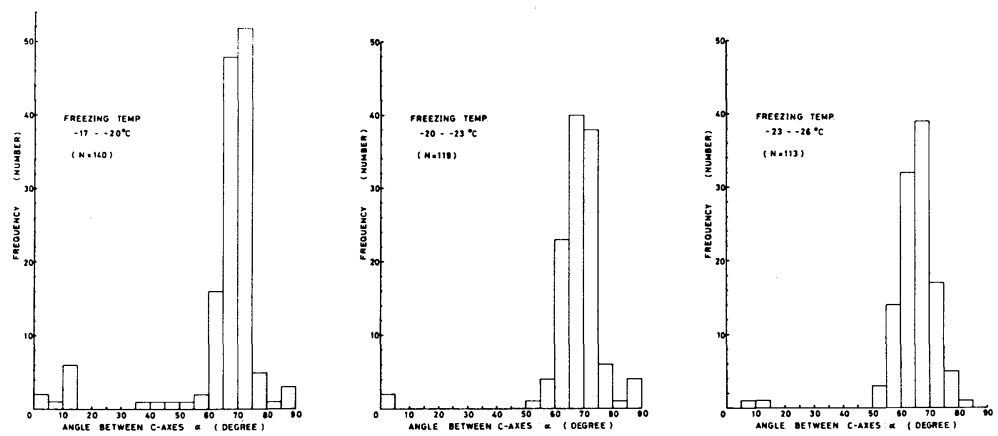

Fig. 4 Frequency distributions of $\alpha$, the angle between the $c$-axes of seeding crystal of ice needle and each crystal making up a frozen hemispheric water drop at each temperature range of $-17 \sim-20^{\circ} \mathrm{C},-20 \sim-23^{\circ} \mathrm{C}$ and $-23 \sim-26^{\circ} \mathrm{C}$.

stages of thin sections by cutting successively from the top to the bottom of one frozen hemispheric water drop. Crystals of the same principal axis continued from the top to the bottom of the water drop with the same pattern of grain boundaries, while the different crystals exceptionally nucleated from the points other than the seeding point.

When hemispheric water drops seeded with a basal plane of an ice needle froze polycrystalline, the axial angles $\alpha$ and $\theta$ showed predominant peaks in their frequency distributions. The angle $\alpha$, defined as the angle between the $c$-axes of seed crystal and each crystal making up frozen water drop, had a predominant peak around $70^{\circ}$ at all cases of three temperature ranges of -17 to $-20^{\circ} \mathrm{C},-20$ to $-23^{\circ} \mathrm{C}$ and -23 to $-26^{\circ} \mathrm{C}$ as shown in Fig. 4. Here the small angle near $0^{\circ}$ means that the $c$-axis of each crystal of a frozen water drop was the same as that of the ice needle. On the other hand, in the frequency distribution on the angle $\theta$, defined as the angle between the $c$-axes of neighbouring two crystals making up frozen water drop, the concentrations were around $70^{\circ}, 55^{\circ}$ and $40^{\circ}$ corresponding to the angle $\theta^{\prime}$ around $120^{\circ}, 60^{\circ}$ and $180^{\circ}$ respectively, as shown in Fig. 5. Here solid circles indicate the cases in which the direction of the normal line of boundary plane between neighbouring two crystals was identified. Open circles indicate the cases in which the direction of the normal line of a boundary plane between neighbouring two crystals was not identified. Open triangles plotted on the line of $\theta^{\prime}=60^{\circ}$ indicate the cases in which the $c$-axis of one crystal of neighbouring two crystals was parallel to that of a seed crystal and the direction of the normal line of a boundary plane between neighbouring two crystals was not identified. Here, $\theta^{\prime}$ stands for the projection of $\theta$ on the plane of a glass slide. In the distributions of the angle $\theta$, angles of $70^{\circ}$ and $55^{\circ}$ concentrated relatively in all temperature ranges in this experiments. Especially, the angle of $70^{\circ}$ dominated at all temperature ranges of -17 to $-26^{\circ} \mathrm{C}$ and the frequency of the angle of $55^{\circ}$ became large with the decrease of temperatures. On the other hand, the frequency of the angle of $40^{\circ}$ was relatively small and distributed in a wide angle of around $40^{\circ}$.

The axial angle between the $c$-axes of neighbouring crystals of penetration twin like frozen water drops, in which two grain boundaries are crossed each other and the facing two crystals have the same direction of the $c$-axis, was summarized in Table 1. The table shows the axial angles of the $c$-axes between the two crystals of twin like frozen water drops and the freezing temperatures of these water drops. As shown clearly in the table, almost all of them had the angle around $70^{\circ}$ in the temperature ranges of -17.2 to $-24.0^{\circ} \mathrm{C}$. This result shows the same tendency as that described in the previous paper (Uyeda and Kikuchi (1976 a)).

\section{Consideration and conclusions}

As described in the previous section, it was shown that when the freezing temperatures decrease, the ratio of polycrystalline to single crystalline increases in the freezing experiments of supercooled hemispheric water drops seeded with a basal plane of an ice needle. This result agreed well with the former workers (Hallett (1964), Magono and Aburakawa (1968) and Pitter and Pruppacher (1973)). However the frequency of single crystalline frozen water drops seeded with a prism plane of an ice needle was by far 

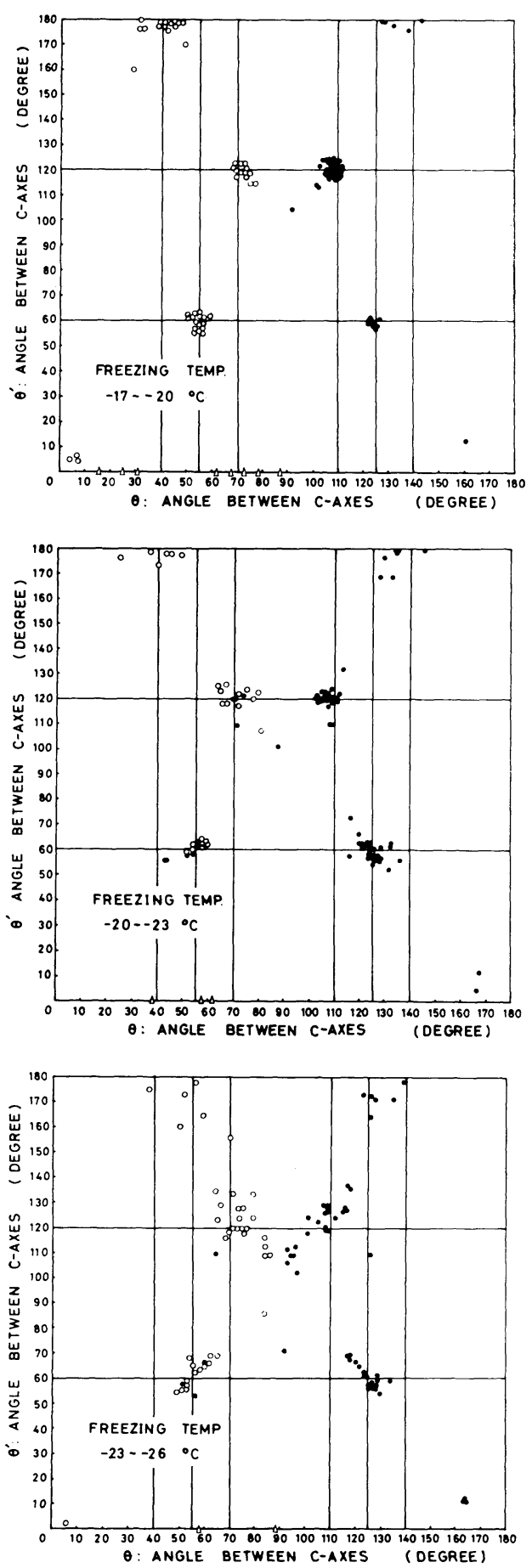

Fig. 5 Distributions of $\theta$, the axial angle between the $c$-axes of neighbouring two crystals of frozen hemispheric water drops at each temperature range of $-17 \sim-20^{\circ} \mathrm{C},-20 \sim$ $-23^{\circ} \mathrm{C}$ and $-23 \sim-26^{\circ} \mathrm{C}$. $\theta^{\prime}$ stands for the projection of $\theta$ on the plane of a glass slide.
Table 1. Axial angles between the $c$-axes of each crystal making up a frozen water drop of a penetration twin-like crystal.

\begin{tabular}{|c|c|}
\hline $\begin{array}{c}\text { Angle between } \\
\text { c-axes } \\
\text { degree) }\end{array}$ & $\begin{array}{c}\text { Freezing } \\
\text { temperature } \\
\left({ }^{\circ} \text { C) }\right.\end{array}$ \\
\hline 71 & -17.2 \\
\hline 74 & -17.5 \\
\hline 74 & -18.5 \\
\hline 74 & -18.6 \\
\hline 73 & -18.8 \\
\hline 69 & -19.6 \\
\hline 71 & -20.5 \\
\hline 72 & -20.7 \\
\hline 75 & -21.4 \\
\hline 72 & -23.1 \\
\hline 85 & -24.0 \\
\hline
\end{tabular}

larger than that of single crystalline frozen water drops seeded with a basal plane of an ice needle. When hemispheric supercooled water drops were seeded with a prism plane of an ice needle, pólycrystallization did not commence from the seeding point. Contrary to this, when the drops were seeded with a basal plane of the similar ice, polycrystallization commences from the seeding point.

Kikuchi and Uyeda (1979) found in natural snow crystals that cloud droplets and small rain drops collected and frozen on surfaces of snow crystals of plane types were single crystals with the same $c$-axis, the different $c$-axis from the substrate snow crystal and polycrystalline. In the snow crystals of prism types, however, almost all of frozen cloud droplets on prism planes were single crystals with the same $c$-axis with the substrate snow crystals. From these results it is concluded that polycrystallization at a seeding point is intimately connected to basal planes of seeding crystals. Therefore, we will consider the effect of basal plane of snow crystals on freezing of water droplets.

The angle $\alpha$ in this experiment, namely the axial angle between the $c$-axes of a seeding crystal and of each crystal making up a frozen water drop, had a predominant peak around $70^{\circ}$. This agrees well with the results of the observations by Lee (1972), Uyeda and Kikuchi (1976 b) and Kobayashi et al. (1976) that the axial angle between the $c$-axes of a spatial branch and a substrate of snow crystal of spatial dendrites had a predominant peak around $70^{\circ}$, for a spatial branch is believed to grow from supercooled cloud droplets collected and frozen on a basal plane of 
a snow crystal of dendritic type.

The experimental result in which the axial angle $\theta$ between the $c$-axes of neighbouring two crystals of a frozen water drop, had peaks around $70^{\circ}$, $55^{\circ}$ and $40^{\circ}$ agrees with the observational results by Lee (1972), Uyeda and Kikuchi (1976 b) and Kobayashi et al. (1976) in that the angle between the $c$-axes of neighbouring two branches of radiating assemblage of dendrites and of neighbouring two bullets of combination of bullets had peaks around $70^{\circ}, 55^{\circ}$ and $40^{\circ}$. In this experiment, the frequency of the angle $\theta$ around $55^{\circ}$ was small at relatively higher temperatures, however it was large at relatively lower temperature below $-20^{\circ} \mathrm{C}$. This also agrees with the observational results by Magono and Lee (1966) that snow crystals of combination of bullets and radiating assemblage of dendrites, in these crystals small peaks in the frequency distribution of the axial angle were around $40^{\circ}$ and $55^{\circ}$, grew at some temperature ranges below $-20^{\circ} \mathrm{C}$. Although, in this experiment, the angle $\theta$ around $70^{\circ}$ was seen also at the temperature range of -17 to $-20^{\circ} \mathrm{C}$, the percentage of polycrystalline water drops frozen at the temperature range of -17 to $-20^{\circ} \mathrm{C}$ was relatively smaller than that frozen at temperatures below $-20^{\circ} \mathrm{C}$. Therefore it is considered that the angle $\theta$ around $70^{\circ}$ is prominent at temperatures below $-20^{\circ} \mathrm{C}$. The small angles around $20^{\circ}$ and $30^{\circ}$ recognized in the previous experiment by Uyeda and Kikuchi (1976) at the temperature above $-20^{\circ} \mathrm{C}$ were not obvious in this experiment. The reason for this is probably that the crystals which commenced freezing at the points apart from the seeding point of a hemispheric water drop were excluded from the measurement, namely the small angles around $20^{\circ}$ and $30^{\circ}$ seems to be affected by these crystals which commenced freezing at the points apart from the seeding point.

Table 1 shows that almost all of frozen water drops had the angle around $70^{\circ}$ between the $c$ axes of two crystals when frozen water drops were though to be penetration twin composed of only two directions of the $c$-axis. This indicates that the axial angle around $70^{\circ}$ between the $c$ axes of neighbouring two crystals dominates when frozen cloud droplets were composed of only two directions of the $c$-axis. There are many examples which exist in nature. In natural polycrystalline snow crystals the frequency of the axial angle of $70^{\circ}$ between the $c$-axes dominates and that of the axial angles of $55^{\circ}$ and $40^{\circ}$ are relatively small comparing the angle of $70^{\circ}$. The reason

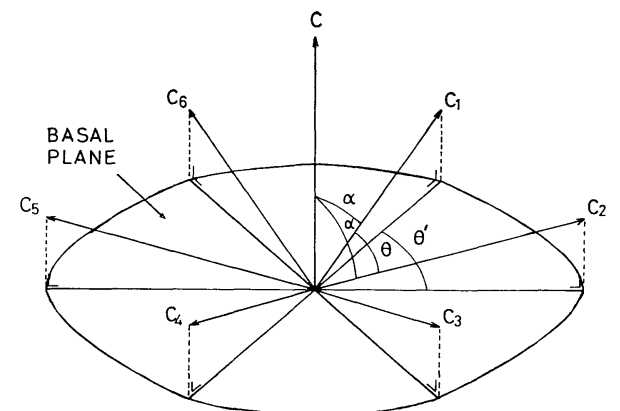

Fig. 6 Schematic figure of the possible $c$-axes of a frozen water drop; $C$ is the direction of the c-axis of seeding crystal and $C_{1}, C_{2}, C_{3}$, $C_{4}, C_{5}$ and $C_{6}$ are the directions of the $c$-axes of each crystals making up a frozen water drop.

for this is considered that frozen cloud droplets are usually composed of only a few crystals, namely the axial angles of $55^{\circ}$ and $40^{\circ}$ between the branches of snow crystals are considered to be made from frozen cloud droplets with many crystals.

Based upon the axial angles of $70^{\circ}, 55^{\circ}$ and $40^{\circ}$ described above, the possible arrangement of the $c$-axes of crystals making up a frozen water droplet is summarized relative to the $c$-axis of a seeding crystal as shown in Fig. 6 . It is considered that the seeding crystal in this figure will be substituted by an air borne tiny broken snow crystal or an ice nucleating substance on the supercooled cloud droplets in natural cloud. An angle between the $c$-axes of neighbouring two crystals will be decided by the combination of two $c$-axes of Fig. 6. For example, the combination of $C_{1}-C_{3}, C_{2}-C_{4}, C_{3}-C_{5},---$ makes the axial angle of $110^{\circ}$, that is the complementary angle, $70^{\circ}$. The combination of $C_{1}-C_{2}, C_{2}-C_{3}, C_{3}-C_{4}$, - - makes the axial angle of $55^{\circ}$ between the $c$-axes of them, and the combination of $C_{1}-C_{4}$, $C_{2}-C_{5}, C_{3}-C_{6},--$ makes the axial angle of $140^{\circ}$, that is the complementary angle, $40^{\circ}$. These angles described above interpret the prominent angles of natural polycrystalline snow crystals. Therefore, the theory which explains the origin of polycrystalline snow crystals grown from frozen cloud droplets three dimensionally must satisfy these arrangements of the directions of the $c$-axes.

\section{Acknowledgements}

The authors express their hearty thanks to Profs. C. Magono and T. Kobayashi, Hokkaido University, for their encouragements and discus- 
sions throughout the course of this study. A part of the expence of this study, especially, the equipment used for this experiment was defrayed by the Special Funds provided in 1972 from the Ito Science Fundation for which Kikuchi is greatly indebted.

\section{References}

Aburakawa, H. and C. Magono, 1972: Temperature dependency of crystallographic orientation of spatial branches of snow crystals. J. Meteor. Soc. Japan, 50, 166-170.

Hallett, J., 1964: Experimental studies of the crystallization of supercooled water. J. Atmos. Sci., 21, $671-682$.

Higuchi, K. and T. Yoshida, 1966: Crystallographic orientation of frozen droplets. Physics of Snow and Ice, Vol. 1 (Inst. Low Temp. Sci. Hokkaido Univ., Sapporo), 79-93.

Kikuchi, K. and K. Ishimoto, 1974: Role of frozen cloud droplets on the growth of snow crystals of certain shapes. J. Fac. Sci., Hokkaido Univ., Ser. VII, 4, 69-80.

- and H. Uyeda, 1979: Cloud droplets and rain drops collected and frozen on the surface of natural snow crystal. J. Meteor. Soc. Japan, 5y, 273-281.

Kobayashi, T., Y. Furukawa, T. Takahashi, and H. Uyeda, 1976: Cubic structure models at the junctions in polycrystalline snow crystals. J. Crystal Growth, 35, 262-267.

Lee, C. W., 1972: On the crystallographic orientation of spatial branches in natural polycrystalline snow crystals. J. Meteor. Soc. Japan, 50, 171-180.

Magono, C. and H. Aburakawa, 1968: Experimental studies on snow crystals of plane type with spatial branches. J. Fac. Sci., Hokkaido Univ., Ser. VII, 3, 85-97.

- and C.W. Lee, 1966: Meteorological classification of natural snow crystals. J. Fac. Sci., Hokkaido Univ., Ser. VII, 2, 321-335.

Murray, W. A. and R. List, 1972: Freezing of water drops. J. Glaciology, 11, 415-429.

Parungo, E. P. and H. K. Weickmann, 1973: Growth of ice crystals from frozen cloud droplets. Beit. zur Phys. Atmos., 46, 289-304.

Pitter, R. L. and H. R. Pruppacher, 1973: A wind tunnel investigation of freezing of small water drops falling at terminal velocity in air. Quart. J. Roy. Met. Soc., 99, 540-550.

Uyeda, H. and K. Kikuchi, 1976a: On the orientation of the principal axis of frozen water droplets. J. Meteor. Soc. Japan, 54, 267-275.

and - 1976b: Remeasurement of axial angle between spatial branches of natural polycrystalline snow crystal. J. Fac. Sci., Hokkaido Univ., Ser. VII, 5, 21-28. and — 1978: Freezing experiment of supercooled water droplets frozen by using single crystal ice. J. Meteor. Soc. Japan, 56, 43-51.

Weickmann, H. K., 1972: Snow crystal forms and their relationship to snowstorms. J. de Recherches Atmospheriques, 6, 603-615.

\section{半球状凍結水滴の結晶主軸の測定}

\section{上田 博*.菊 地 勝 弘 \\ 北海道大学理学部地球物理学教室}

凍結雲粒の多結晶化の機構を解明するために, 過冷却した直径約 $1 \mathrm{~mm}$ の半球状の水滴の凍結実験を行なった。 半球状の水滴は $-17 \sim-20^{\circ} \mathrm{C},-20 \sim-23^{\circ} \mathrm{C},-23 \sim-26^{\circ} \mathrm{C}$ の各温度範囲で単結晶の針状の霜のベーサル面やプ リズム面を接触させることにより凍結した。半球状の水滴を針状の霜のベーサル面で接触させ涷結させた場合に，顕 著な多結晶化が怙こった。凍結に用いた霜の結晶と半球状の凍結水滴の結晶主軸間のなす角度は, $-17 \sim-26^{\circ} \mathrm{C} の$ 全ての温度領域に颃いて, $70^{\circ}$ 飞顕著なピークが認められた。半球状の凍結水滴の隣り合ら結晶相互の主軸のなす角 度は $70^{\circ}, 55^{\circ}, 40^{\circ}$ 付近にピークがあった。今回の実験に打いて現われたこれらの角度をるとにして, 過冷却水滴が 凍結する際の結晶主軸のとりらる方向が議論された。それらの配置は Fig. 6 亿示されている。

* 現在所属 : 国立防災科学技術センター 